\title{
Problems facing women who seek a career in paediatrics
}

In $1980,35 \%$ of doctors graduating in the United Kingdom and $56 \%$ of those choosing a paediatric career were women; ${ }^{1}$ but $83 \%$ of consultant paediatricians are men. ${ }^{2}$ The long training, involving moves of post and place, presents particular problems for married women, and increasing competition, inflexible career structures, and financial restrictions contribute to their growing difficulties. Furthermore, medical school expansion continues despite medical unemployment, and about $50 \%$ of students are now female.

\section{Choice of career}

Unanticipated changes in domestic circumstances make career choice difficult for women. On beginning postgraduate training in paediatrics many are single, competing without disadvantage. Pressure to acquire qualifications, particularly the specifically paediatric part 2 examination for membership of the Royal College of Physicians, may lead to undesirably early specialisation.

Those women marrying early in their training frequently opt out and those marrying later may feel committed to an extremely demanding course, difficult to combine with domestic commitments. In addition, there is little informed guidance available concerning potential problems.

\section{Geographical problems}

Our postgraduate training system assumes ability to apply for posts at each grade, wherever these are available. Married women doctors may experience untimely moves because of their husbands' career requirements. The number of posts appropriate in grade, time, and place are few, particularly outside London, and those not requiring rotation to a distant hospital are even fewer. Consequently, women doctors may suffer gaps in employment, uncertainty, and loss of confidence. Moves to small communities may make training unsatisfactory or impossible. Obviously for some couples the woman's career takes precedence. Some have to commute long distances and some may even live apart.

\section{Parenthood}

A few women achieve full time training despite having children. Others consider sleep depletion, erratic diet, and exposure to acquired and congenital infections to be unacceptable during pregnancy. Symptoms may be incompatible with on call commitments. Many women are unwilling to relinquish their children's early care to nannies and few hospitals provide crèches. Most women are unwilling to delay childbearing until they become consultants.

\section{Stopping work, retainer schemes, and other options}

Women who stop work soon get out of touch and find that keeping abreast by reading is difficult with small children. The Doctors' Retainer Scheme ${ }^{34}$ helps by allowing women to work as little as half a day per month, but regional waiting lists may occur and we need to know how easily training grades can be re-entered. Clinical assistant posts lack tenure and are not normally accreditable as part of postgraduate training, and clinical medical officer posts may become less frequently available with increasing incorporation into career structures.

\section{Part time training}

Health authorities may establish personal part time senior house officer and registrar posts, but these are limited by restricted funding, and if created, frequently prove unsatisfactory, particularly in provision of experience in acute medicine. ${ }^{5}$ Part time senior registrar training is organised by the DHSS. ${ }^{34}$ Short listed candidates compete at annual interviews for Central Manpower Committee approval, the number allowed being calculated from the success rates of applicants for full time posts. Hence part time posts should be neither easier nor harder to obtain than full time ones.

Manpower approval, however, does not guarantee employment. Regional funding must be requested, educational approval obtained, a regional interview committee satisfied, and consultants found who will provide training. The process may be lengthy. Obtaining funding can be particularly difficult, varying among health regions. Manpower approval is normally lost if a post is not established within nine months, necessitating re-application. Although manpower approval moves with the holder, funding does not, so further negotiations for money, uncertainty, and difficulty in re-establishing work may ensue. Being supernumerary and therefore 
'non-essential', these posts are jeopardised by financial restrictions.

'Domestic commitments' considered to justify part time training are ill defined, and interpretation of this term varies from region to region. Geographical immobility, though often preventing acquisition of full time posts, is not universally considered adequate justification without children. The posts tend to carry the image of 'easy options' of low status, occasionally with some justification. ${ }^{5}$ The quality of training, particularly in acute paediatrics, may be inferior to that obtained by full time senior registrars. ${ }^{6}$

\section{New proposals}

A working party is currently considering (so far without concensus) incorporation of existing supernumerary posts into regional senior registrar establishments. ${ }^{7}$ Each 'whole time equivalent' post could thereafter be used for either one full time or two part time trainees: presumably effectively a job sharing scheme. Unfortunately, suitable partners are rarely available. The British Medical Association's job sharing register has so far successfully matched only one pair of doctors in any specialty, and employers would probably favour full time candidates. The potential for geographical mobility of the posts would presumably be lost.

Do we not need to retain a supernumerary system, though making it centrally and reliably funded? Current 'low status' is probably attributable as much to past selection procedures and to failure of consultants to feel committed to part time training, as to supernumerary status per se. Doctors are already theoretically free to share posts.

\section{Training for what?}

Little is known of the outcome for part time senior registrars; still less for part time registrars and senior house officers and those in retainer schemes. Nineteen paediatric part time senior registrars approved in 1974-1979 were contacted in $1981 .^{8}$ Sixteen were still part time senior registrars and only one was a consultant. Later follow up may be more encouraging. The difficulty in obtaining a consultancy locally in a competitive field is obvious. Specialisation may be restricted by immobility, and many would not risk training for a specific post.

Part time consultant posts are rarely available for those whose domestic commitments continue. Accredited trainees may be told they are over qualified for associate specialist posts, and in any case financial restrictions limit their availability. Funding for part time training may be withdrawn soon after accreditation, possibly resulting in unemployment.

\section{Conclusion}

Paediatric careers are frequently prohibitively difficult for married women, especially those with children, though their personal experience should be valued. Part time training opportunities need active protection in a competitive field, and funding must be reliable. These schemes must accommodate the geographical problems women face. Hospitals should provide crèches.

More part time consultancies are needed if considerable wastage of training is to be avoided. Expansion of community paediatric services should provide some opportunities to redress this need and development of the associate specialist grade would help. Detailed follow up of part time trainees is needed, so that informed advice can be given to junior doctors, particularly since the increasing number of female graduates can no longer be directed to the few remaining 'shortage specialties'. Unfortunately domestic commitments reduce the likelihood of many women serving on national committees where their views could have influence on this undesirable situation.

\section{ReEs \\ 46 Clifton Park Road, Bristol BS8 3HN}

\section{References}

1 Parkhouse J, Campbell MG, Hambleton RA, Philips PR. Career preferences of doctors qualifying in the United Kingdom in 1980. Health Trends 1983;15:12-4.

${ }^{2}$ Department of Health and Social Security. Medical and dental staffing prospects in the NHS in England and Wales, 1983. Health Trends 1984;16:25-9.

3 Department of Health and Social Security. Opportunities for part-time training in the NHS for doctors and dentists with domestic commitments, disability or ill-health. Personnel Memorandum PM 79 (3). London: DHSS, 1979.

${ }^{4}$ Council for Postgraduate Medical Education in England and Wales. Part-time in medicine. London: CPME, 1981.

${ }^{5}$ Burke CW, Black NA. Part time senior registrars, registrars, and senior house officers in general medicine and its specialties: a report to the Royal College of Physicians. $\mathrm{Br}$ Med J 1983;287:1040-4.

6 Burke CW. Part time training in general medical specialties: is it any use? $\mathrm{Br}$ Med $J$ 1983;287:1037-9.

7 Joint Consultants Committee. Part-time senior registrar training. Br Med $J$ 1985;290:408.

${ }^{8}$ Department of Health and Social Security. Medical and dental staffing and prospects in the NHS in England and Wales, 1981. Health Trends 1982;14:28-33. 